\title{
OXYGEN TRANSPORT IN NANOSTRUCTURED LANTHANUM
}

\section{MANGANITES}

\author{
Ilenia Rossetti ${ }^{*}$, Mattia Allieta, Cesare Biffi, Marco Scavini \\ Dip. Chimica, Università degli Studi di Milano, CNR-ISTM center \\ and INSTM Milano-Università Unit \\ v. C. Golgi 19, I-20133 Milano, Italy
}

\begin{abstract}
Methods and models describing oxygen diffusion and desorption in oxides have been developed for slightly defective and well crystallised bulky materials. Does nanostructuring change the mechanism of oxygen mobility? In such a case, models should be properly checked and adapted to take into account new material properties.

In order to do so, temperature programmed oxygen desorption and thermogravimetric analysis, either in isothermal or ramp mode, have been used to investigate some nanostructured $\mathrm{La}_{1-\mathrm{x}} \mathrm{A}_{\mathrm{x}} \mathrm{MnO}_{3 \pm \delta}$ samples ( $\mathrm{A}=\mathrm{Sr}$ and $\mathrm{Ce}, 20-60 \mathrm{~nm}$ particle size) with perovskite-like structure. The experimental data have been elaborated by means of different models to define a set of kinetic parameters able to describe oxygen release properties and oxygen diffusion through the bulk. Different rate-determining steps have been identified, depending on the temperature range and oxygen depletion of the material. In particular, oxygen diffusion shows rate-limiting at low temperature and with low defect concentration, whereas oxygen recombination at the surface seems to be the rate-controlling step at high
\end{abstract}


temperature. However, the oxygen recombination step is characterised by an activation energy much lower than that for diffusion.

In the present paper oxygen transport in nanosized materials is quantified by making use of widely diffused experimental techniques and by critically adapting to nanoparticles suitably chosen models developed for bulk materials.

Keywords: Temperature programmed desorption; Thermogravimetric analysis; Oxygen diffusion; Oxygen mobility; Perovskite-like materials.

\section{INTRODUCTION}

Mixed oxides with perovskitic structure find applications as catalysts in many processes such as deep or partial oxidation of hydrocarbons and $\mathrm{VOC}$ or $\mathrm{NO}_{\mathrm{x}}$ decomposition. They are also candidates as materials for Solid Oxide Fuels Cells (SOFC) [1-3]. Perovskites are mixed oxides with general formula $\mathrm{ABO}_{3 \pm \delta}$, where $\mathrm{A}$ is usually a lanthanide or alkali-earth ion and $\mathrm{B}$ is a transition metal ion. Typically, the physical-chemical and catalytic properties may be tuned by doping at $\mathrm{A}$ and/or $\mathrm{B}$ site, leading to widely different $\mathrm{A}_{1-\mathrm{x}} \mathrm{A}_{\mathrm{x}}{ }^{\prime} \mathrm{B}_{1-\mathrm{y}} \mathrm{B}_{\mathrm{y}} \mathrm{O}_{3 \pm \delta}$ formulations. The redox properties of the B ion and oxygen mobility through the lattice play a role of paramount importance for the application of such materials. The development of sound models for their description is therefore crucial.

Oxygen diffusion tailors the dynamics of oxidation reactions, which are usually interpreted as the result of two mechanisms. The suprafacial one is active at relatively low temperature $(\mathrm{T}<$ $673 \mathrm{~K})$ and involves surface oxygen, whereas the intrafacial one, occurring at higher temperature, is related to oxygen mobility as well as release from the bulk. This, in turn, depends on the redox properties of the B ion [4]. 
The most common techniques used to characterise ion reducibility and oxygen release properties are Temperature Programmed Reduction (TPR) and Desorption (TPD). For instance, Misono et al. [5-7] highlighted two peaks upon heating in TPD experiments on perovsiktes: $\alpha$, due to the low-temperature release from the surface of oxygen deriving from $\mathrm{O}^{-}$and $\mathrm{O}^{2-}$ species, and $\beta$, occurring at higher temperature, due to $\mathrm{O}^{2-}$ species from the bulk. An additional $\alpha_{2}$ peak has been sometimes observed with $\mathrm{LaCoO}_{3 \pm \delta}[8,9]$. All these species are exemplified in Fig.1. The correlation of the $\alpha$-peak intensity with surface area confirms its origin from surface oxygen species. In contrast to that, the $\beta$-peak appears regardless of the surface area and has been assumed to be an indication of oxygen mobility through the bulk: bulk oxygen ions diffuse towards the surface to feed the desorption process. The characterisation of materials for SOFCs $[10,11]$ also allowed concluding that oxygen diffusion is faster along the grain boundaries than in the crystal bulk. In addition, we recently described a method, based on TPR and TPD analysis, to evaluate oxygen non-stoichiometry for $\mathrm{LaCoO}_{3 \pm \delta}$ samples. We proposed also a simple correlation between desorption/reduction data and catalytic activity [9].

While oxygen diffusion properties of microstructured materials have been investigated in depth, there is a substantial lack of knowledge in the field of nanostructured systems, where surface properties and crystal boundaries may be predominant. Nevertheless, nanostructured materials and catalysts are gaining ever increasing importance for applications were oxygen transport properties govern the performance.

Actually, oxygen diffusion properties may deeply change from bulky to nanostructured materials. In fact, the diffusion path towards the surface in nanomaterials is limited and grain boundaries play a major role. Moreover, a higher concentration of defects may be present as compared to bulk samples. As a consequence, proper characterisation tools should be used and models should be derived to interpret these properties. 
Transient experiments based on the assessment of the re-equilibration rate of a sample subject to a gradient of the oxygen chemical potential were proposed for bulk materials [12], when chemical diffusion is the rate-controlling step (RDS). Other useful characterisation methods are: (i) Isotopic Oxygen Exchange [13-15]; (ii) Electrical Conductivity Relaxation [16]; (iii) Thermogravimetric Analysis (TGA). The latter technique seems less complex and more suitable for routine characterisation by means of widely available equipment.

TGA experiments may be carried out in either step mode by measuring the weight loss in isothermal conditions under controlled atmosphere [17], or in ramp mode, following a linear temperature programme [18].

In the present investigation we processed oxygen release data via TPD and TGA analysis for a set of lanthanum manganite samples $\left(\mathrm{La}_{1-\mathrm{X}} \mathrm{A}_{\mathrm{X}} \mathrm{MnO}_{3 \pm \delta}, \mathrm{A}=\mathrm{Sr}, \mathrm{x}=0,0.1,0.2\right.$ and $\mathrm{A}=\mathrm{Ce}$, $\mathrm{x}=0.1$ ) prepared in nanocrystalline form. These were selected as relevant materials for oxidation nanocatalysts in different applications. Possible different mechanisms for oxygen release have been suggested and their relevant kinetic parameters were calculated by making use of well known and relatively simple techniques.

\section{MATERIALS AND METHODS}

\subsection{Sample preparation and characterisation}

The samples were prepared by flame pyrolysis [19-22] and basically characterised, as extensively described in [23]. Sample compositions are reported in Table 1. Particle size was determined by SEM analysis on a LEICA LEO 1420 Scanning Electron Microscope and found out to be $c a$. 20-60 $\mathrm{nm}$ for all samples. Specific surface area (S.S.A.) was measured by $\mathrm{N}_{2}$ adsorption-desorption on a Micromeritics ASAP 2010 apparatus (Table 1). 


\subsection{TPD - MS analysis}

The analysis was carried out on a TPD-TPR apparatus equipped with six independent gassupplying lines and a quadrupolar mass spectrometer (MS, MKS, PPT Residual Gas Analyser) [24]. The sample powder $(0.2-0.3 \mathrm{~g})$, pressed and crushed to $0.15-0.25 \mathrm{~mm}$ particles, was loaded into a quartz tubular reactor and pre-treated at $1073 \mathrm{~K}(10 \mathrm{~K} / \mathrm{min})$ under He flow $\left(30 \mathrm{~cm}^{3} / \mathrm{min}\right)$. Pre-saturation with oxygen was achieved in air flow $\left(30 \mathrm{~cm}^{3} / \mathrm{min}\right)$ at $1023 \mathrm{~K}$ for $1 \mathrm{~h}$. After cooling in air to room temperature, the sample was heated again in $\mathrm{He}$ under conditions identical to those of the pre-treatment.

\subsection{TGA analysis}

TGA analysis was carried out with a Perkin Elmer TGA7 instrument on ca. 20-35 mg of sample (sensitivity $10^{-5} \mathrm{~g}$ ) either in step or ramp mode.

The step mode analysis was performed after pre-treating and pre-saturating the sample as reported in the previous paragraph by using $\mathrm{N}_{2}$ as inert gas instead of He. The temperature was then set to $843 \mathrm{~K}$ in $\mathrm{N}_{2}$ flow for $4 \mathrm{~h}$. Further steps followed up to $1023 \mathrm{~K}$ (50 K step).

In ramp mode, a heating rate $b=10 \mathrm{~K} / \mathrm{min}$ was used in $\mathrm{N}_{2}$ flow from room temperature (r.t.) up to $1073 \mathrm{~K}$. The analysis was performed on the as prepared sample and on three aliquots of different weight, pre-activated in $20 \mathrm{~cm}^{3} / \mathrm{min}$ of air at $1023 \mathrm{~K}$ for $1.5 \mathrm{~h}$.

\section{RESULTS AND DISCUSSION}

\subsection{TPD $-\mathrm{O}_{2}$}

TPD-MS spectra of $\mathrm{La}_{1-\mathrm{x}} \mathrm{A}_{x} \mathrm{MnO}_{3 \pm \delta}$ samples show a $\beta$ peak onset at $T \approx 800 \mathrm{~K}$. $\alpha$ peaks were observed for $\mathrm{A}=\mathrm{Ce}$ and $\mathrm{A}=\mathrm{Sr}$ only for $\mathrm{x}=0.2$. Owing to variable signal intensity of the $\mathrm{MS}$ spectra, all the patterns were normalised by calculating $I_{\text {norm }}=\left(I_{i}-I_{0}\right) /\left(I_{\max }-I_{0}\right)$, where $I_{i}$ is 
the signal intensity of the $i$-th point, $I_{0}$ is the intensity of the baseline and $I_{\max }$ that of the $\beta$ peak maximum. The normalised spectra related to the $\mathrm{LaMnO}_{3 \pm \delta}$ and $\mathrm{La}_{0.9} \mathrm{Ce}_{0.1} \mathrm{MnO}_{3 \pm \delta}$ samples are reported as an example in Fig.1.

The TPD reactor was approximated as a differential plug flow reactor (PFR), since the variation of oxygen partial pressure across the reactor was found to be lower than $5 \%$ of the total oxygen amount available in the oxide. Concentration gradients in radial direction and back-mixing were neglected and every TPD datum was interpreted as a measurement in a differential PFR reactor operating at the $i$-th temperature. The reaction rate is generally expressed as

$$
r_{i}=f\left(\left[O_{2}\right], n\right) k\left(T_{i}\right)
$$

where $r_{i}$ is the observed reaction (desorption) rate at $T_{i}, f\left(\left[\mathrm{O}_{2}\right], n\right)$ is a function of oxygen concentration and of the reaction order $n$ and $k\left(T_{i}\right)$ is the kinetic constant in the Arrhenius form:

$$
k\left(T_{i}\right)=A \exp \left(-\frac{E_{a}}{R T_{i}}\right)
$$

$A$ being the pre-exponential factor (the units depend on the reaction order) and $E_{a}\left(\mathrm{~kJ} \mathrm{~mol}^{-1}\right)$ the activation energy. Eq. (1) can thus be rewritten as

$$
r_{i}=\frac{F_{H e}}{V_{\text {sample }}}\left(\frac{P_{i}}{P_{0}}-1\right)
$$

$F_{H e}$ being molar flow rate of the carrier gas, $P_{i}$ the oxygen partial pressure detected by the spectrometer at $T_{i}$ and $P_{0}$ the background oxygen partial pressure.

The following equilibrium reactions were introduced to describe oxygen desorption, in particular referring to the $\beta$-peak.

$$
\begin{array}{ll}
O_{0}^{2-} \Leftrightarrow O_{\text {surf. }}^{2-} & \text { (oxygen diffusion) } \\
2 \mathrm{O}_{\text {surf. }}^{2-} \Leftrightarrow O_{2(\text { ads. })}+4 e^{-} & \text {(surface recombination) }
\end{array}
$$


$O_{2(a d s)} \Leftrightarrow O_{2(g)}$

(oxygen desorption)

The four electrons appearing in R.2 have been added formally for charge balance, as they are essentially involved in the reduction of $\mathrm{Mn}^{\mathrm{n}+}$ surface sites.

(R.1) equilibrium represents oxygen diffusion through the bulk and the kinetic constant could be denoted as D, i.e. a transport or chemical diffusion coefficient. (R.2) describes oxygen recombination on the surface and the order of reaction was assumed to be 2 with respect to the $\mathrm{O}^{2-}$ species. (R.3) features desorption of molecular oxygen and it is rated as very fast in the high temperature range investigated $(T>673 \mathrm{~K})$.

The corresponding kinetic equations may be written as follows $(\tau(\mathrm{s})$ standing for the contact time):

$$
\begin{aligned}
& d\left[O_{\text {surf }}^{2-}\right] / d \tau=D\left[O_{0}^{2-}\right]=r(1) \\
& d\left[O_{2, \text { ads }}\right] / d \tau=k_{\text {recomb. }}\left[O_{\text {surf. }}^{2-}\right]^{2}=r(2)
\end{aligned}
$$

Following a different approach, the rate of oxygen desorption can be calculated using the Polanyi - Wigner equation [25-27]:

$r_{\text {des }}=k_{n} \Theta^{n}$

where $\Theta=N_{a d s} / N_{\text {mono }}$ is the surface coverage, $N_{a d s}$ and $N_{\text {mono }}$ are the moles of oxygen adsorbed on the surface and those referring to a monolayer, respectively, and $k_{n}$ is the kinetic constant. Hence, one may write Eq. 3 as:

$$
r_{i}=\left[\frac{F_{H e}}{V_{c a t}}\left(\frac{P_{i}}{P_{0}}-1\right)\right]=\left[\frac{1}{\tau}\left(\frac{P_{i}}{P_{0}}-1\right)\right]=v_{n} \Theta^{n} \exp \left(-\frac{E_{a}}{R T}\right)
$$

The following logarithmic form of Eq. 7 was used for the data, providing an estimation of the activation energy from the slope of the plots $\ln r_{\mathrm{i}} v s .1 / T$.

$$
\ln r_{i}=\ln v_{n}+n \ln \Theta-\frac{E_{a}}{R T}=\ln A^{\prime}\left(v_{n}, \Theta\right)-\frac{E_{a}}{R T}
$$

A detailed example of data evaluation using this model is reported for $\mathrm{LaMnO}_{3 \pm \delta}$ only. The results for other samples are summarised in Table 2. 
The data in the temperature range of the $\beta$-peak $(800-1073 \mathrm{~K})$ were extracted and processed by calculating $r_{\mathrm{i}} / \mathrm{s}^{-1}$ according to Eqs. 3 and 8. The related results are reported in Fig. 2 and 3. As shown in Fig. 3, the Polanyi - Wigner $(P W)$ plot is not linear in the whole temperature range and different temperature ranges are stated, where the linear behaviour according to Eq. 8 is followed. In particular, at least two distinct regimes appear, one of them at low temperatures (Regime(i) in Fig. 3), the other at higher temperatures (Regime(iii) in Fig. 3). A transition zone is evident for every sample, which is labelled as Regime(ii). The linear interpolation of the data produced values of $E_{a}$ and $A^{\prime}$ for every sample and for each regime. The results are summarised in Table 2 , where $\bar{T}(\mathrm{~K})$ represents the average temperature at which a particular mechanism is expected to be active.

A proportional relationship between $E_{\mathrm{a}}$ and $A^{\prime}$ has been evidenced. The numerical correlation between experimental kinetic parameters is called Kinetic Compensation Effect (KCE) [28, 29] and has been often detected for heterogeneous reaction kinetics (see e.g. [29] and references therein). In particular, a linear correlation is usually reported between $\ln A$ and $E_{a}$. For our data we found that $\ln A=0.125(1) E_{\mathrm{a}}+0.73(17)$. In order to take into account the KCE, a slightly different approach was also tried, following a re-parameterisation of the PW equation in the following form [30]:

$$
\ln r_{i} / r_{j}=\frac{E_{a}}{R}\left(\frac{1}{T_{j}}-\frac{1}{T_{i}}\right)
$$

where $r_{\mathrm{i}}$ and $r_{\mathrm{j}}$ are the experimental reaction rates at $T_{i}$ and $T_{j}$, respectively. One of these temperatures $\left(T_{j}\right)$ was chosen as fixed reference value, so as to decrease the number of parameters to be estimated (ideally only the activation energy). This is actually a commonly adopted approach, well described in the literature [30].

The linear regression carried out e.g. in the temperature range of Regime $(i)$ taking $T_{j}=$ $\bar{T}$ resulted in $E_{a}=173 \mathrm{~kJ} / \mathrm{mol}$, perfectly matching up to the previous estimation. However, varying $E_{a}$ values were calculated with different reference $T_{j}$, as reported in Fig. 4 and as 
already noticed elsewhere [30]. It is clear that when $T_{j} \gg \bar{T}$, the activation energy related to a given regime decreases abruptly. This is a further confirmation that different kinetic regimes exist at various temperatures. Therefore, the re-parameterised PW equation should be used only by selecting suitable reference $T_{j}$ to define the temperature range where the model compares well with the data [30].

The re-parameterised PW equation was applied to each sample and, as shown in the parity plot reported in Fig.5, the estimated activation energy $\left(E_{\mathrm{a}, \text { repar }}\right)$ is always close to the value found without re-parameterisation $\left(E_{\mathrm{a}}\right)$.

Another interesting example is constituted by sample $\mathrm{La}_{0.8} \mathrm{Sr}_{0.2} \mathrm{MnO}_{3 \pm \delta}$. The results of the TPD data elaboration following the re-parameterised PW model are detailed in Fig.6.

Only two regimes are well distinguishable with mean activation energy $E_{a}=130 \pm 1 \mathrm{~kJ} / \mathrm{mol}$ and $E_{a}=80 \pm 2 \mathrm{~kJ} / \mathrm{mol}$, respectively.

By keeping the activation energy of Regime $(i)$ for $\mathrm{LaMnO}_{3 \pm \delta}$ as a reference $\left(E_{a}=170 \pm 2\right.$ $\mathrm{kJ} / \mathrm{mol}$ in Table 2), a lower activation energy was obtained for $\mathrm{La}_{0.8} \mathrm{Sr}_{0.2} \mathrm{MnO}_{3 \pm \delta}$, as already reported by Berenov et al. [31].

Considering the kinetic parameters retrieved for the $x=0,0.1,0.2$ samples of $\mathrm{La}_{1-\mathrm{x}} \mathrm{Sr}_{\mathrm{x}} \mathrm{MnO}_{3 \pm \delta}$, Regime $(i)$ may be reasonably attributed to an oxygen diffusion process through the lattice for the fully oxidised sample. At relatively low temperature the activation energy is high due to hindered oxygen mobility. When oxygen release progressively occurs, vacancies form, which favour oxygen transport across the bulk. This leads to a transition zone, where oxygen diffusion is still the rate-regulating step, but the increase of defects concentration progressively lowers the activation energy (Regime(ii)).

As a strong support to this interpretation, a lower activation energy was evaluated for samples doped with increasing amounts of $\mathrm{Sr}^{2+}$, which induces the formation of a non-negligible amount of defects, making oxygen diffusion easier if compared to the undoped, less defective sample. 
Regime(iii) was attributed to the surface recombination of oxygen, becoming kinetically limiting at high temperature only, when oxygen diffusion is much faster. Regime(iii) is obviously characterised by an activation energy by far lower than for diffusion.

For $\mathrm{La}_{0.9} \mathrm{Ce}_{0.1} \mathrm{MnO}_{3 \pm \delta}$ the activation energy calculated for Regime(ii) is, instead, higher than for Regime(i). Consequently, the oxygen desorption mechanism is expected to be different from $\mathrm{La}_{1-\mathrm{x}} \mathrm{Sr}_{\mathrm{x}} \mathrm{MnO}_{3 \pm \delta}$. Indeed, the larger Ce valence should trigger a different oxygen defects chemistry (e.g. interstitial oxygen ions instead of oxygen vacancies).

\subsection{TGA analysis}

The rate of oxygen desorption was supposed to be dependent on $T$ and on the residual sample weight at a given time $t$. The conversion $\alpha$ at the time $t$ was defined as follows [18]:

$\alpha=\frac{W_{0}-W_{t}}{W_{0}-W_{\infty}}$

$W_{0}, W_{t}$ and $W_{\infty}$ being sample weights at the beginning of the analysis (either of the thermal ramp or of the isothermal step, depending on the operating mode), at time $t$ and at the end of the analysis, respectively. The conversion was assumed to vary versus time as [18]:

$\frac{d \alpha}{d t}=k(T) f(\alpha)$

where $k(T)$ is expressed in the Arrhenius form. $f(\alpha)$ is the so called kinetic function or physical-geometrical model function [32], depending on the underlying reaction mechanism, and possibly being determined through experiments on materials with a well-defined geometry. This function is tabulated [32], though it is often possible to make reference to empirical models [33].

After analysing the TGA data according to Eqs. 10 and 11, it was thereby possible to estimate the activation energy $E_{T G}$ and the pre-exponential factor $A_{T G}$, using a particular form of $f(\alpha)$ and resorting to standardised methods [34]. 
The results derived from Eq. 11 differ substantially when operating under isothermal or nonisothermal operating conditions. Indeed, when temperature is constant, also $k(T)$ is constant, whereas under non-isothermal conditions $k(T)$ continuously varies in the experimental temperature range. One needs therefore to switch over to the so called integral methods, regarding $A_{T G}$ as independent of temperature and using an integral form of the Arrhenius equation:

$\int_{T_{0}}^{T} k_{T G}(T) d T=A_{T G} \int_{T_{0}}^{T} \exp \left(-\frac{E_{T G}}{R T}\right) d T$

On one hand, the temperature-programmed analysis allows the investigation of a temperature range broader than in the case of the isothermal step procedure, since in the latter the material may undergo significant transformations even during the starting equilibration period [18]. On the other hand, the ramp procedure reveals a stronger dependence of the estimated kinetic parameters on $W_{0}$, on the heating rate $b(\mathrm{~K} / \mathrm{min})$, as well as on gas composition, reactor geometry, sample size and porosity $[18,32,35]$.

\subsubsection{Step TGA}

When TGA analysis is carried out following isothermal steps, $k$ is constant at every temperature stage. When a suitable form of $f(\alpha)$ is known, it is possible to calculate $k\left(T_{i}\right)$ and estimate $E_{T G-s t e p}$. The so-called Friedman iso-conversion method [36, 37] is based on the linearisation of Eq. 11, which enables the estimation of $E_{T G \text {-step }}$ without using any a priori hypothesis on the form of $f(\alpha)$ :

$\ln \left(\frac{d \alpha}{d t}\right)_{\alpha}=\ln A_{T G-s t e p}+\ln [f(\alpha)]-\frac{E_{T G-s t e p}}{R T_{\alpha}}$

The left hand side of Eq. 13 includes the rate corresponding to a conversion $\alpha$, as derived at different temperatures $T_{\alpha}$ [34]. 
The detailed elaboration is reported also in this case for the sample $\mathrm{LaMnO}_{3 \pm \delta}$, only, whose thermogram, collected in step mode, is depicted in Fig.7.

TGA data shown in Fig.7 were elaborated through Eq. 10 and plotted vs. $t$, as displayed in Fig. $8 a$ for each temperature. The corresponding conversion rates $(\mathrm{d} \alpha / \mathrm{dt})$ are shown in Fig. $8 b$.

According to Eq. 13 and by plotting $\ln (d \alpha / d t)_{\alpha} v s .1 / T_{\alpha}$ one derives directly $E_{T G \text {-step }}$ from the slope and the factor $\left(\ln A_{T G \text {-step }}+\ln [f(\alpha)]\right)$ from the intercept on the vertical axis of the interpolating line. Data calculated using Eq. 13 are shown in Fig. 9 and the values of the apparent $E_{T G \text {-step }}$ gathered from all the samples at iso-conversion are reported in Table 3. For our purposes, the terms $\ln A_{T G \text {-step }}+\ln [f(\alpha)]$ did not need to be considered.

\subsubsection{TGA under non isothermal conditions}

In the case of non isothermal TG experiments (TG-ramp), carried out with constant heating rate $b(=10 \mathrm{~K} / \mathrm{min})$, the conversion rate should be expressed as [18]:

$$
\frac{d \alpha}{d T}=\frac{A}{b} \exp \left(-\frac{E_{a}}{R T}\right) f(\alpha)
$$

Eq. 14 can be integrated over the whole temperature range being considered [18]:

$$
\int_{0}^{\alpha} \frac{d \alpha}{f(\alpha)}=\frac{A}{b} \int_{T_{0}}^{T} \exp \left(-\frac{E_{a}}{R T}\right) d T
$$

The term on the left hand side is generally called $g(\alpha)$ and contains information about the reaction mechanism and some physical chemical properties of the sample. The most common formulations of $g(\alpha)$ are tabulated [18]. The term on the right hand side is the so called Arrhenius integral [38] and does not have analytical solutions. Different methods for the evaluation of this integral have been proposed [18, 38] and logarithmic forms of these approximations are given by Orfão et al. [18]. 
However, a simplified approach adopts the Coats and Redfern [39] form of the integral in Eq. 15, which is suitable for $E_{a} / R T>10$ [40]:

$\ln [g(\alpha)]-2 \ln T \approx \ln \left[\frac{A R}{b E}\right]-\frac{E_{a}}{R T}$

Eq. 16 is used to evaluate the most suitable form of $g(\alpha)$ and the related kinetic parameters.

\subsubsection{Selection of the $g(\alpha)$ model function}

The most suitable model function may be selected by model comparison on the basis of data fitting or of a priori assumption on the mechanism for a given sample of known composition and morphology. As an example, a thermogravimetric study on $\mathrm{LaCrO}_{4 \pm \delta}$ under isothermal conditions [41] showed how to apply the Hancock-Sharp [42] method to determine the likeliest $g(\alpha)$ function. The method is based on the Avrami - Erofe'ev equation, valid for solid state heterogeneous kinetics:

$\ln [-\ln (1-\alpha)]=\ln B+m \ln t$

where $B$ is a constant commonly related to the nucleation frequency of reactive grains and $m$ is a constant depending on the system geometry. Ten $g(\alpha)$ functions were reported to belong to three main groups: 1) $D(\alpha)$ models for diffusion-controlled reactions; 2) $F(\alpha)$ and $A(\alpha)$ models for nucleation-controlled reactions; 3) $R(\alpha)$ models for reactions controlled by grain boundaries. By plotting the left hand side term of Eq. 17 vs. $\ln t$ the slope $m$ obtained by linear regression should be compared with the values reported in Table 4.

This approach has been applied at first to the step mode TGA analysis in order to identify the most correct model function, and then used to interpret the TGA data collected in ramp mode. The Hancock-Sharp plot for $\mathrm{LaMnO}_{3 \pm \delta}$ is displayed in Fig. 10 for data in the range $0.25 \leq \alpha \leq 0.80$ and for all the temperatures.

The calculated values of $m$ were found to be between 0.66 and $0.69\left(\mathrm{R}^{2}>0.991\right)$ in the whole temperature range, clearly suggesting that the most appropriate kinetic model is diffusional, 
This is also in good agreement with data reported elsewhere for $\mathrm{LaCrO}_{4 \pm \delta}$ [42], where for $m=$ 0.68 the diffusional model allowed obtaining the best matching with TG data.

The non isothermal TG-ramp data of sample $\mathrm{LaMnO}_{3 \pm \delta}$ were then elaborated according to the diffusional models described in Table 4 and, for comparison, also with the $F_{1}$ and $F_{2}$ model functions.

Finally, the model functions used to fit the data and the pertinent results are summarised in Table 5.

The diffusional models $D_{2}, D_{3}, D_{4}$ showed the best accordance with the experimental data. Furthermore, from the calculated $E_{T G-R a m p}$ values the validity condition of the model, E/RT > 10 , was verified a posteriori. The $E_{T G-R a m p}$ data evaluated for $\mathrm{LaMnO}_{3 \pm \delta}$ by assuming a diffusion-limited reaction are in fairly good agreement with the desorption results reported in Table 2 for Regime $(i)$, once more confirmed to be the signature of a rate-determining step representing oxygen diffusion.

\subsection{Comparison with literature data}

Activation energies for oxygen diffusion in the $\mathrm{La}_{1-\mathrm{x}} \mathrm{Sr}_{\mathrm{x}} \mathrm{MnO}_{3 \pm \delta}$ as a function of $x$ are shown in Fig. 11. The values extracted from TPD data analysis and referring to Regime(i), attributed to a diffusional rate-determining step for the fully oxidised sample, were compared with the activation energy for oxygen tracer diffusion in the bulk found using the ${ }^{18} \mathrm{O} /{ }^{16} \mathrm{O}$ isotope exchange method $[31,43,44]$. For $\mathrm{LaMnO}_{3 \pm \delta}$ and $\mathrm{La}_{0.8} \mathrm{Sr}_{0.2} \mathrm{MnO}_{3 \pm \delta}$ samples (empty triangle and square in Fig. 11) also the activation energies for oxygen tracer surface exchange are reported $[31,44]$.

By comparing our activation energy values with the literature data one may notice a poor agreement with results for bulk diffusion in sintered materials as such. Conversely, the values obtained with the present TPD method agree well with those obtained on the basis of the isotope tracer diffusion equation, including boundary conditions which take into account a 
surface exchange coefficient [45]. This is very encouraging, since it corroborates the importance of surface effects during the investigation of diffusion behavior in nanostructured materials and validates the present approach.

As to the critical evaluation of the different methods used in the present work, the kinetic parameters estimated in the TG-step mode are based on isotherms collected in the 923-1023 K temperature range and are related to a conversion level (for oxygen release) of $c a$. 0.5. They should therefore be compared with TPD- $\mathrm{O}_{2}$ data assigned to Regime(ii) or Regime(iii). The activation energies estimated with all the methods used in the present investigation are summarised in Fig. 12. The activation energy for thermal desorption decreases with increasing conversion due to the transition from a chemical diffusion controlling mechanism to a surface recombination one. In addition, the application of literature models to our TGstep data provide evidence of a diffusion controlled mechanism (vide supra). We may thus conclude that $E_{T G \text {-step }}(\alpha \approx 0.5)$ corresponds conceptually to $E_{a}$ for Regime(ii). When comparing the calculated data for each sample (Fig. 12) one can notice that both the TG-step and the TPD (Regime(ii)) methods are able to qualitatively predict the variation of the activation energy for oxygen release upon doping. However, the absolute value of the activation energy calculated by the two techniques is markedly different. The activation energies estimated from isothermal TG analysis are compatible with oxygen migration from $\mathrm{BO}_{6}$ octahedra in adjacent vacancies in the perovskite lattice $(\sim 83 \mathrm{~kJ} / \mathrm{mol}[46]$, or $\sim 70 \mathrm{~kJ}$ /mol [47] for $\mathrm{LaMnO}_{3 \pm \delta}$ ), but they seem largely underestimated when compared with other literature data for bulk materials (see Fig. 11). This further highlights the role of defects (and of the higher concentration of oxygen vacancies and grain boudaries in nanostructured materials with respect to microstructured ones) on oxygen diffusion.

In any case, the dependence of $E_{T G \text {-step }}$ and that of $E_{a}$ for Regime(i) and Regime(ii) on $\mathrm{LaMnO}_{3 \pm \delta}$ doping clearly reveal that these regimes are correlated to oxygen diffusion through the bulk. In fact, doping with an ion $\left(\mathrm{Sr}^{2+}\right)$ of lower valence compared to La increases the 
concentration of defects, thus promoting the oxygen transport across the lattice and decreasing the activation energy for this reaction step.

\section{CONCLUSIONS}

Different experimental approaches have been adopted to evaluate oxygen diffusion and release for nanostructured lanthanum manganite samples. Different kinetic regimes have been identified. At low temperature the process is kinetically limited by oxygen transport through the lattice, with decreasing activation energy upon increasing defects concentration. Doping with an ion $\left(\mathrm{Sr}^{2+}\right)$ of valence lower than that of $\mathrm{La}^{3+}$ induces a decrease of the activation energy for oxygen transfer. A further rate-determining mechanism is surface recombination of oxygen, becoming predominant only at very high temperature, when oxygen mobility is sufficiently fast. Consistent results were obtained by combining independent analytical methods that make use of dynamic oxygen release, such as temperature programmed desorption or thermogravimetry under non isothermal conditions. In contrast to this, isothermal TG analysis correctly indicates a diffusion limited process and the effect of doping on the activation energy for oxygen release, though the estimation of the activation energy for oxygen diffusion was in poor accordance with previous results.

\section{REFERENCES}

[1] M.A. Peña, J.L.G. Fierro, Chem. Rev., 2001, 101,1981. 
[2] R. Leanza, I. Rossetti, L. Fabbrini, C. Oliva, L. Forni, Appl. Catal. B: Environ., 2000, 28, 55.

[3] I. Rossetti, L. Forni, Appl. Catal. B: Environ., 2001, 33, 345.

[4] R.J.H. Voorhoeve, J.P. Remeika, D.W. Johnson, Science, 1973, 180, 62.

[5] T. Nitadori, T. Ichiki, M. Misono, Bull. Chem. Soc. Jpn., 1988, 61, 621.

[6] T. Nitadori, M. Misono, J. Catal., 1985, 93, 459.

[7] T. Nakamura, M. Misono, Y. Yoneda, Bull. Chem. Soc. Jpn., 1982, 55, 394.

[8] S. Royer, F. Bérubé, S. Kaliaguine, Appl. Catal. A: Gen, 2005, 282, 273.

[9] I. Rossetti, C. Biffi, L. Forni, Chem. Eng. J., 2010, 162, 768.

[10] S. Kaliaguine, A. Van Neste, V. Szabo, J.E. Gallot, M. Bassir, R. Muzychuck, Appl.Catal. A: Gen., 2001, 209, 345.

[11] N. Sakai, T. Horita, H. Yokokawa, M. Dokiya, Solid State Ion., 1996, 86, 1273.

[12] J.E. ten Elshof, M.H.R. Lankhorst, H.J.M. Bouwmeester, Solid State Ion., 1997, 99, 15.

[13] S. Royer, D. Duprez, S. Kaliaguine, J. Catal., 2005, 234, 364.

[14] J.M. Bassat, M. Petitijean, J. Fouletier, C. Lalanne, G. Caboche, F. Mauvy, J.C. Grenier, Appl. Catal. A: Gen., 2005, 289, 84.

[15] T. Ishihara, J.A. Kilner, M. Honda, N. Sakai, H. Yokokawa, Y. Takita, Solid State Ion., 1998, 113, 593.

[16] J.A. Lane, S.J. Benson, D. Waller, J.A. Kilner, Solid State Ion., 1999, 121, 201.

[17] M. Scavini, L. Malavasi, L. Mollica, Sol. State. Science, 2004, 6, 1187.

[18] J.J.M. Orfão, F.G. Martins, Thermochim. Acta, 2002, 390, 195.

[19] G.L. Chiarello, I. Rossetti, L. Forni, J. Catal., 2005, 236, 251.

[20] G.L. Chiarello, I. Rossetti, P. Lopinto, G. Migliavacca, L. Forni, Catal. Today, 2006, 117, 549. 
[21] G.L. Chiarello, I. Rossetti, P. Lopinto, G. Migliavacca, L. Forni, Appl. Catal. B: Environ., 2007, 72, 218.

[22] G.L. Chiarello, I. Rossetti, P. Lopinto, G. Migliavacca, L. Forni, Appl. Catal. B: Environ., 2007, 72, 227.

[23] I. Rossetti, O. Buchneva, C. Biffi, R. Rizza, Appl. Catal. B: Environ., 2009, 89, 383.

[24] L. Forni, M. Toscano, P. Pollesel, J. Catal., 1991, 130, 392.

[25] D.A. King, Surf. Sci., 1975, 47, 384.

[26] A.M. de Jong, J.W. Niemantsverdriet, Surf. Sci., 1990, 233, 355.

[27] P.A. Redhead, Vacuum, 1962, 12, 203.

[28] A.K. Galwey, M.E. Brown, Thermochim. Acta, 1997, 300, 107.

[29] A.K. Galwey, D.G. Bettany, M. Mortimer, Int. J. Chem. Kinet., 2006, 38, 689.

[30] M. Schwaab, J.C. Pinto, Chem. Eng. Sci., 2007, 62, 2750.

[31] A.V. Berenov, J.L. MacManus-Driscoll, J.A. Kilner, Solid State Ion., 1999, 122, 41.

[32] N. Koga, J. Thermal. Anal., 1997, 49, 45.

[33] J. Šesták, G. Berggren, Thermochim. Acta, 1971, 3, 1.

[34] M.E. Brown, M. Maciejewski, S. Vyazovskin, R. Nomen, J. Sempere, A. Burnham, J. Opfermann, R. Strey, H.L. Anderson, A. Kemmler, R. Keuleers, J. Janssens, H.O. Desseyn, C.-R. Li, T.B. Tang, B. Roduit, J. Malek, T. Mitsuhashi, Thermochim. Acta, 2000, $355,125$.

[35] L.A. Pérez-Maqueda, A. Ortega, J.M. Criado, Thermochim. Acta, 1996, 277, 165.

[36] H. Friedman, J. Polym. Sci., 1965, 50, 183.

[37] S. Vyazovkin, New J. Chem., 2000, 24, 913.

[38] A.K. Burnham, R.L. Braun, Energy Fuels, 1999, 13, 1.

[39] J.J.M. Orfão, AIChE J., 2007, 53, 2905.

[40] L.A. Pérez-Maqueda, J.M. Criado, F.J. Gotor, Int. J. Chem. Kin., 2002, 34, 184.

[41] A. Furusaki, H. Konno, R. Furuichi, Thermochim Acta, 1995, 253, 253. 
[42] J.D. Hancock, J.H. Sharp, J. Am. Ceram. Soc., 1972, 55, 74.

[43] I. Yasuda, K. Ogasawara, M. Hishinuma, T. Kawada, M. Dokiya, Solid State Ion., 1996, 86-87, 1197.

[44] R.A. De Souza, J.A. Kilner, J.F. Walker, Mater. Lett., 2000, 43, 43.

[45] J. Crank, in:, The Mathematics of Diffusion, $2^{\text {nd }}$ Ed., Oxford University Press, New York, 1975.

[46] M. Cherry, M.S. Islam, C.R. Catlow, J. Solid State Chem., 1995, 118, 125.

[47] A. Belzner, T.M. Gür, R.A. Huggins, Solid State Ion., 1992, 57, 327. 


\section{TABLES}

Table 1: Sample compositions and corresponding specific surface area (S.S.A.) [23].

\begin{tabular}{|c|c|}
\hline Sample & S.S.A. $\mathbf{m}^{2} / \mathbf{g}$ \\
\hline $\mathrm{LaMnO}_{3 \pm \delta}$ & 56 \\
\hline $\mathrm{La}_{0.9} \mathrm{Sr}_{0.1} \mathrm{MnO}_{3 \pm \delta}$ & 51 \\
\hline $\mathrm{La}_{0.8} \mathrm{Sr}_{0.2} \mathrm{MnO}_{3 \pm \delta}$ & 70 \\
\hline $\mathrm{La}_{0.9} \mathrm{Ce}_{0.1} \mathrm{MnO}_{3 \pm \delta}$ & 84 \\
\hline
\end{tabular}

Table 2: Kinetic parameters calculated from Eq. 4. $\bar{T}=$ average temperature of the kinetic regime being considered. Temperature ranges are in parentheses.

\begin{tabular}{|c|c|c|c|}
\hline Sample & $\mathrm{LaMnO}_{3 \pm \delta}$ & $\mathrm{La}_{0.9} \mathrm{Sr}_{0.1} \mathrm{MnO}_{3 \pm \delta}$ & $\mathrm{La}_{0.9} \mathrm{Ce}_{0.1} \mathrm{MnO}_{3 \pm \delta}$ \\
\hline $\begin{array}{c}\bar{T}(\mathrm{~K}) \\
\text { Regime }(i)\end{array}$ & $\begin{array}{c}884 \\
(837<\mathrm{T}<931 \mathrm{~K})\end{array}$ & $\begin{array}{c}890 \\
(842<\mathrm{T}<938 \mathrm{~K})\end{array}$ & $\begin{array}{c}886 \\
(832<\mathrm{T}<940 \mathrm{~K})\end{array}$ \\
\hline $\begin{array}{c}\bar{T}(\mathrm{~K}) \\
\text { Regime (ii) }\end{array}$ & $\begin{array}{c}964 \\
(936<\mathrm{T}<992 \mathrm{~K})\end{array}$ & $\begin{array}{c}963 \\
(940<\mathrm{T}<986 \mathrm{~K})\end{array}$ & $\begin{array}{c}969 \\
(942<\mathrm{T}<996 \mathrm{~K})\end{array}$ \\
\hline $\begin{array}{c}\bar{T}(\mathrm{~K}) \\
\text { Regime (iii) }\end{array}$ & $\begin{array}{c}1027 \\
(998<\mathrm{T}<1056 \mathrm{~K})\end{array}$ & $\begin{array}{c}1021 \\
(987<\mathrm{T}<1055 \mathrm{~K})\end{array}$ & $\begin{array}{c}1012 \\
(998<\mathrm{T}<1026 \mathrm{~K})\end{array}$ \\
\hline $\begin{array}{c}E_{a}(\mathrm{~kJ} / \mathrm{mol}) \\
\text { Regime }(i)\end{array}$ & $172 \pm 2$ & $147 \pm 2$ & $96 \pm 2$ \\
\hline $\begin{array}{l}\ln \left(\mathrm{A}^{\prime} / \mathrm{s}^{-1}\right) \\
\text { Regime }(i)\end{array}$ & $22.6 \pm 0.3$ & $19.1 \pm 0.2$ & $12.6 \pm 0.2$ \\
\hline $\begin{array}{c}E_{a}(\mathrm{~kJ} / \mathrm{mol}) \\
\text { Regime }(i i)\end{array}$ & $85 \pm 2$ & $91 \pm 1$ & $133 \pm 2$ \\
\hline $\begin{array}{c}\ln \left(\mathrm{A}^{\prime} / \mathrm{s}^{-1}\right) \\
\text { Regime (ii) }\end{array}$ & $11.3 \pm 0.2$ & $11.9 \pm 0.1$ & $17.3 \pm 0.2$ \\
\hline $\begin{array}{l}E_{a}(\mathrm{~kJ} / \mathrm{mol}) \\
\text { Regime (iii) }\end{array}$ & $40 \pm 1$ & $49 \pm 1$ & $47 \pm 1$ \\
\hline $\begin{array}{l}\ln \left(\mathrm{A}^{\prime} / \mathrm{s}^{-1}\right) \\
\text { Regime(iii) }\end{array}$ & $5.9 \pm 0.1$ & $6.8 \pm 0.1$ & $6.9 \pm 0.1$ \\
\hline
\end{tabular}


Table 3: $E_{T G-s t e p}$ for all samples.

\section{$\mathrm{LaMnO}_{3 \pm \delta} \quad \mathrm{La}_{0.9} \mathrm{Sr}_{0.1} \mathrm{MnO}_{3 \pm \delta} \quad \mathrm{La}_{0.8} \mathrm{Sr}_{0.2} \mathrm{MnO}_{3 \pm \delta} \quad \mathrm{La}_{0.9} \mathrm{Ce}_{0.1} \mathrm{MnO}_{3 \pm}$}

$\begin{array}{llllc}\boldsymbol{E}_{\boldsymbol{T G} \text {-step }}(\mathbf{k J} / \mathbf{m o l}) & 61.4 & 39.1 & \mathbf{\delta} & 53.4\end{array}$

Table 4: $g(\alpha)$ functions [18,42] and $m$ coefficients for solid state reactions [42]. $D(\alpha)$ : models for reactions controlled by diffusion; $F(\alpha)$ and $A(\alpha)$ : models for reactions controlled by nucleation; $R(\alpha)$ : models for reactions controlled by grain boundaries.

\begin{tabular}{|c|c|c|}
\hline Model & $g(\alpha)=k \mathrm{t}$ & $\boldsymbol{m}$ \\
\hline$D_{1}(\alpha)$ & $\alpha^{2}=k \mathrm{t}$ & 0.62 \\
\hline$D_{2}(\alpha)$ & $(1-\alpha) \ln (1-\alpha)+\alpha=k \mathrm{t}$ & 0.57 \\
\hline$D_{3}(\alpha)$ & {$\left[1-(1-\alpha)^{1 / 3}\right]^{2}=k \mathrm{t}$} & 0.54 \\
\hline$D_{4}(\alpha)$ & $-2 / 3 \alpha)-(1-\alpha)^{2 / 3}=k \mathrm{t}$ & 1.00 \\
\hline$F_{1}(\alpha) \mathrm{n}=1$ & $\alpha /(1-\alpha)=k \mathrm{t}$ & - \\
\hline$F_{2}(\alpha) \mathrm{n}=2\left(^{*}\right)$ & $1-(1-\alpha)^{1 / 2}=k \mathrm{t}$ & 1.11 \\
\hline$R_{2}(\alpha)$ & $1-(1-\alpha)^{1 / 3}=k \mathrm{t}$ & 1.07 \\
\hline$R_{3}(\alpha)$ & {$[-\ln (1-\alpha)]^{1 / 2}=k \mathrm{t}$} & 1.24 \\
\hline Zero order & {$[-\ln (1-\alpha)]^{1 / 3}=k \mathrm{t}$} & 2.00 \\
\hline$A_{2}(\alpha)$ & {$[a b l e-11 \mathrm{Ref}[18]$.} & 3.00 \\
\hline$A_{3}(\alpha)$ & & \\
\hline
\end{tabular}

(*) This function form is taken from Table 1 in Ref. [18]. 
Table 5: Kinetic parameters evaluated from TG-ramp data for $\mathrm{LaMnO}_{3 \pm \delta}$ according to selected models based on diffusion $(D)$ or nucleation $(F)$ controlled mechanisms.

\begin{tabular}{|c|c|c|c|}
\hline Model & $\boldsymbol{E}_{\text {TG-Ramp }}(\mathbf{k J} / \mathbf{~ m o l})$ & $\ln \left(\boldsymbol{A}_{\text {TG-Ramp }} / \mathbf{s}^{-1}\right)$ & $\boldsymbol{R}^{2}$ \\
\hline$F_{1}$ & 100 & 6 & 0.987 \\
\hline$F_{2}$ & 149 & 13 & 0.917 \\
\hline$D_{1}$ & 150 & 10 & 0.980 \\
\hline$D_{2}$ & 169 & 13 & 0.990 \\
\hline$D_{3}$ & 193 & 9 & 0.989 \\
\hline$D_{4}$ & 177 & 13 & 0.993 \\
\hline
\end{tabular}




\section{FIGURE CAPTIONS}

Figure 1: TPD - MS spectra of samples (1) $\mathrm{LaMnO}_{3 \pm \delta}$, (2) $\mathrm{La}_{0.9} \mathrm{Ce}_{0.1} \mathrm{MnO}_{3 \pm \delta}$. Normalised intensity of the MS signal vs. temperature. The standard labels used to identify desorption peaks are highlighted.

Figure 2: $\beta$-peak desorption rate for $\mathrm{LaMnO}_{3 \pm \delta}$.

Figure 3: Polanyi-Wigner $(P W)$ plot for $\mathrm{LaMnO}_{3 \pm \delta}$, reporting the logarithm of the oxygen desorption rate $\left(r_{i}\right)$ at each temperature vs. temperature ${ }^{-1}$. The linear interpolation of the data in different temperature ranges allows determining the activation energy for oxygen release in different kinetic regimes.

Figure 4: Estimated value of the activation energy $\left(E_{a}\right)$ obtained by selecting different reference temperatures $\left(T_{j}, r_{j}\right)$ for $\mathrm{LaMnO}_{3 \pm \delta}$ in Regime $(i)$. The constant dashed line represents $E_{a}$ calculated via the Polanyi-Wigner equation without re-parameterisation.

Figure 5: Activation energy $\left(E_{a}\right)$ evaluated with and without re-parameterisation of the Polanyi-Wigner equation for $\mathrm{LaMnO}_{3 \pm \delta}(\bullet), \mathrm{La}_{0.9} \mathrm{Sr}_{0.1} \mathrm{MnO}_{3 \pm \delta}(\circ)$ and $\mathrm{La}_{0.9} \mathrm{Ce}_{0.1} \mathrm{MnO}_{3 \pm \delta}(\boldsymbol{\varpi})$.

Figure 6: Activation energy $\left(E_{a}\right)$ estimated from Eq. 11 for $\mathrm{La}_{0.8} \mathrm{Sr}_{0.2} \mathrm{MnO}_{3 \pm \delta}$. Effect of the selected reference temperature $\left(T_{j}\right)$.

Figure 7: TGA in step mode for sample $\mathrm{LaMnO}_{3 \pm \delta}$. The solid line denotes the sample weight, the dotted line the thermal programme.

Figure 8: $(a)$ Conversion $(\alpha)$ as defined in Eq.10 vs. time $(t)$ at various temperatures; $(b)$ Conversion rate, as defined in Eq. 11, vs. conversion $(\alpha)$ at different temperatures: $T=873 \mathrm{~K}$ $(\bullet), T=923 \mathrm{~K}(\circ) T=973 \mathrm{~K}(\boldsymbol{\nabla}) T=1023 \mathrm{~K}(\Delta)$.

Figure 9: Logarithm of the conversion rate $\ln (d \alpha d d t)_{\alpha}$ for $\mathrm{LaMnO}_{3 \pm \delta}$ vs. reciprocal temperature $\left(1 / T_{\alpha}\right)$ at which the respective conversion was attained. The data points are reported from $\alpha=0.30$ to $\alpha=0.80$, with step $\Delta \alpha=0.10$. 
Figure 10: Hancock-Sharp plot for $\mathrm{LaMnO}_{3 \pm \delta}$, i.e. $\ln (-\ln (1-\alpha))$ vs. $\ln t(\alpha=$ conversion, $t=$ time $)$ at different temperature. $T=873 \mathrm{~K}(\bullet), T=923 \mathrm{~K}(\circ), T=973 \mathrm{~K}(\boldsymbol{\bullet}), T=1023 \mathrm{~K}(\square)$.

Figure 11: Comparison of $\mathrm{La}_{1-\mathrm{x}} \mathrm{Sr}_{\mathrm{x}} \mathrm{MnO}_{3 \pm \delta}$ activation energy $\left(E_{a}\right)$ with literature data for oxygen diffusion as a function of $x:(\diamond)[43],(\boldsymbol{\square}, \square)[44],(\boldsymbol{\Delta}, \triangle)[31],(\bigcirc)$ activation energy from the TPD data of this work $(\operatorname{Regime}(i))$.

Figure 12: Activation energy $\left(E_{a}\right)$ for oxygen desorption estimated by different methods and

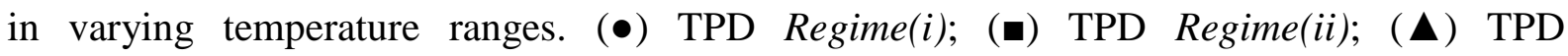
Regime(iii); ( $\square$ ) TGA-step; ( $\times$ ) TGA-ramp. For TGA-ramp the activation energy value obtained using model $D_{4}$ was chosen (see Table 5). 
Figure 1: TPD - MS spectra of samples (1) $\mathrm{LaMnO}_{3 \pm \delta}$, (2) $\mathrm{La}_{0.9} \mathrm{Ce}_{0.1} \mathrm{MnO}_{3 \pm \delta}$. Normalised intensity of the MS signal vs. temperature. The standard labels used to identify desorption peaks are highlighted.
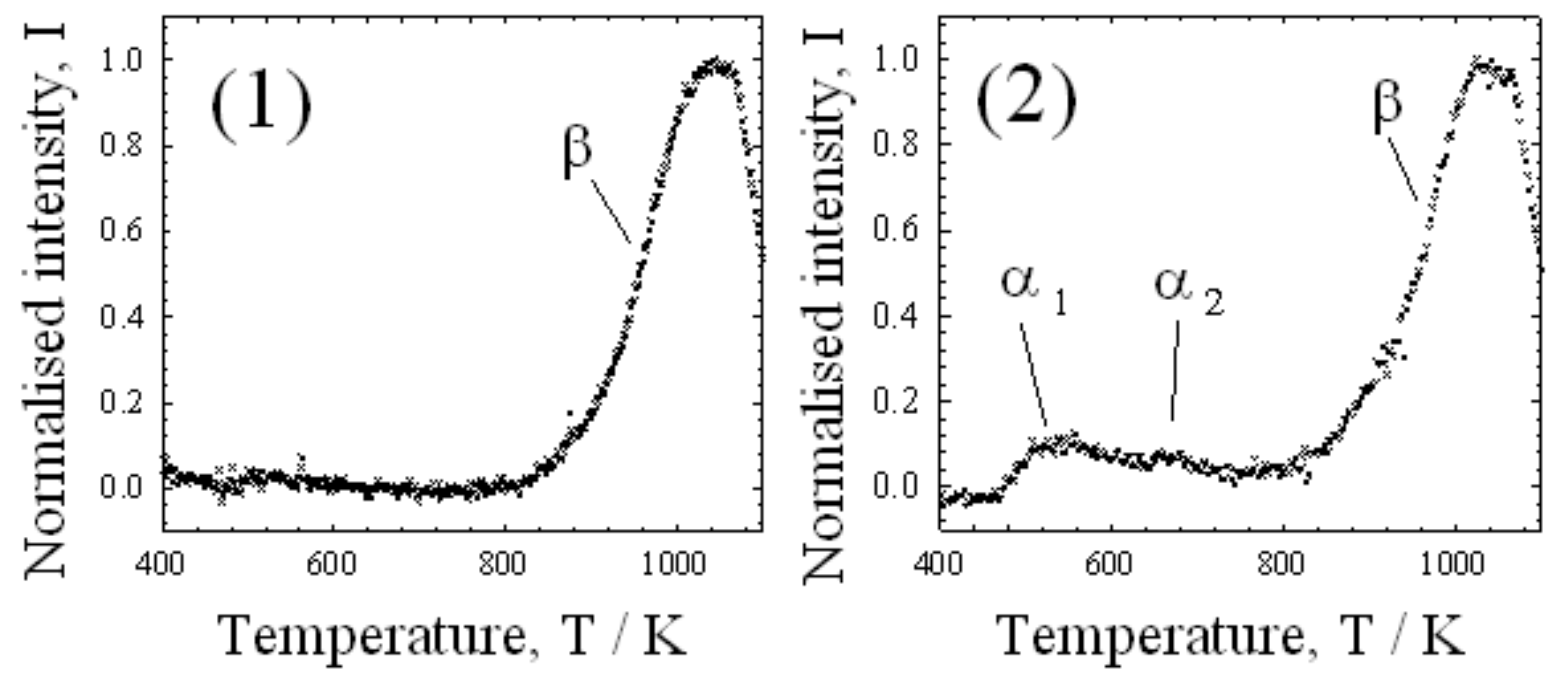

Figure 2: $\beta$-peak desorption rate for sample $\mathrm{LaMnO}_{3 \pm \delta}$.

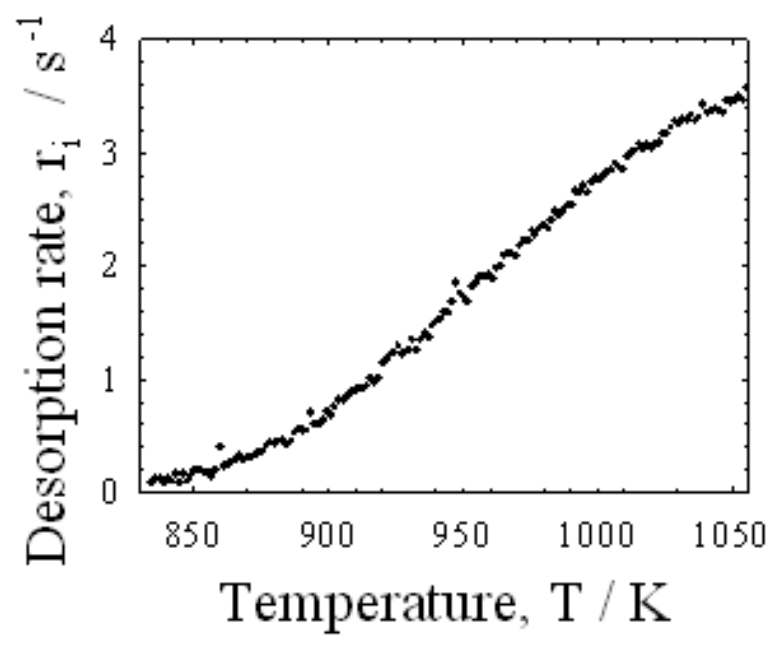


Figure 3: Polanyi-Wigner $(P W)$ plot for $\mathrm{LaMnO}_{3 \pm \delta}$, reporting the logarithm of the oxygen desorption rate $\left(r_{i}\right)$ at each temperature vs. temperature ${ }^{-1}$. The linear interpolation of the data in different temperature ranges allows determining the activation energy for oxygen release in different kinetic regimes.

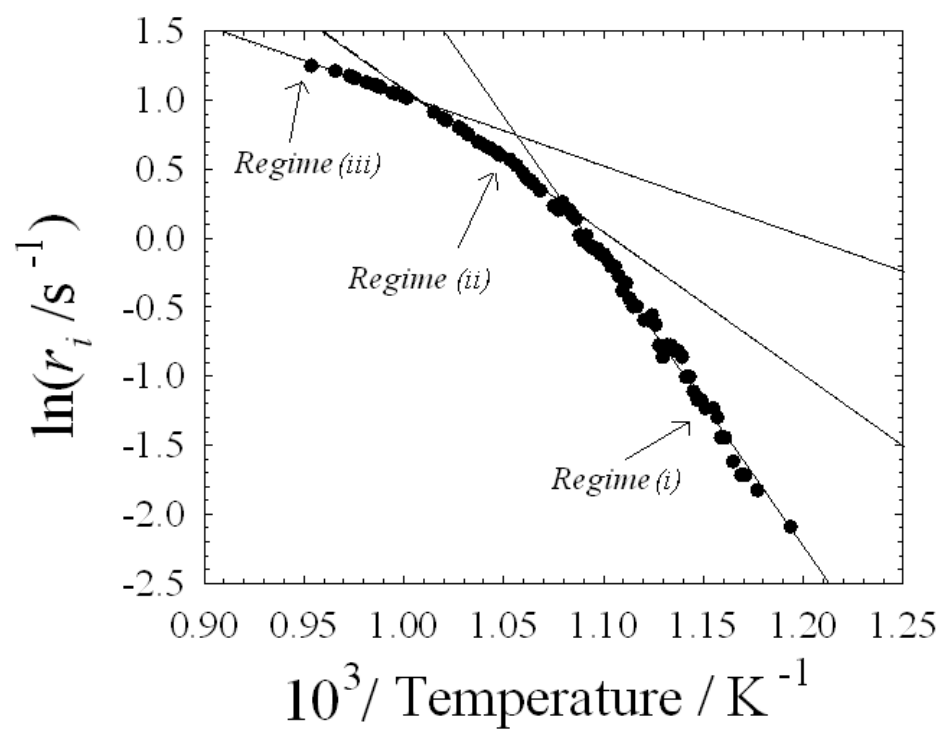

Figure 4: Estimated value of the activation energy $\left(E_{a}\right)$ obtained by selecting different reference temperatures $\left(T_{j}, r_{j}\right)$ for $\mathrm{LaMnO}_{3 \pm \delta}$ in Regime $(i)$. The constant dashed line represents $E_{a}$ calculated via the Polanyi-Wigner equation without re-parameterisation.

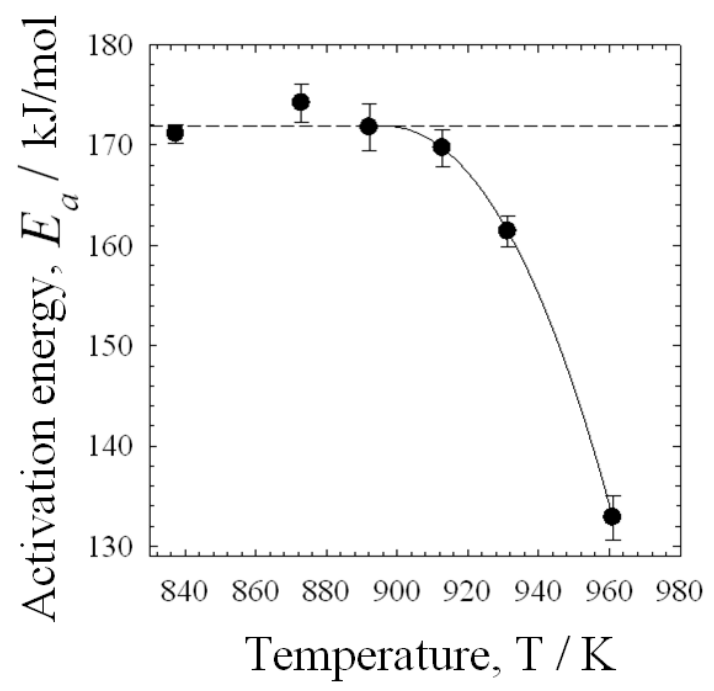


Figure 5: Activation energy $\left(E_{a}\right)$ evaluated with and without re-parameterisation of the Polanyi-Wigner equation for $\mathrm{LaMnO}_{3 \pm \delta}(\bullet), \mathrm{La}_{0.9} \mathrm{Sr}_{0.1} \mathrm{MnO}_{3 \pm \delta}(\circ)$ and $\mathrm{La}_{0.9} \mathrm{Ce}_{0.1} \mathrm{MnO}_{3 \pm \delta}(\boldsymbol{\bullet})$.

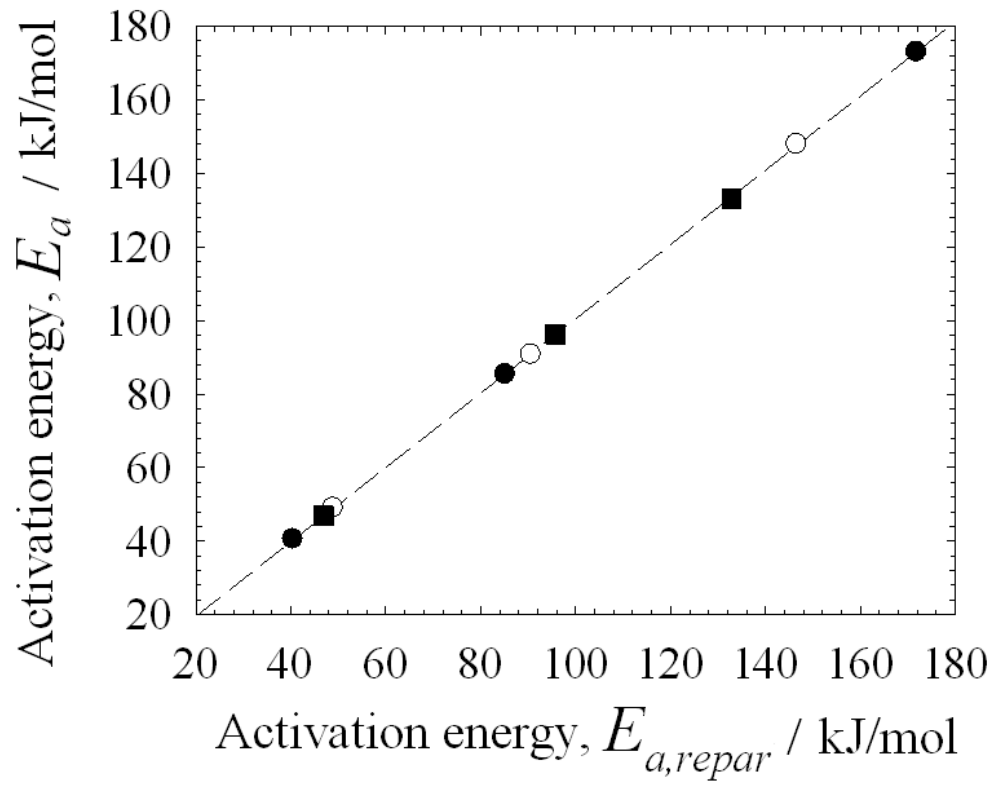

Figure 6: Activation energy $\left(E_{a}\right)$ estimated from Eq. 11 for $\mathrm{La}_{0.8} \mathrm{Sr}_{0.2} \mathrm{MnO}_{3 \pm \delta}$. Effect of the selected reference temperature $\left(T_{j}\right)$.

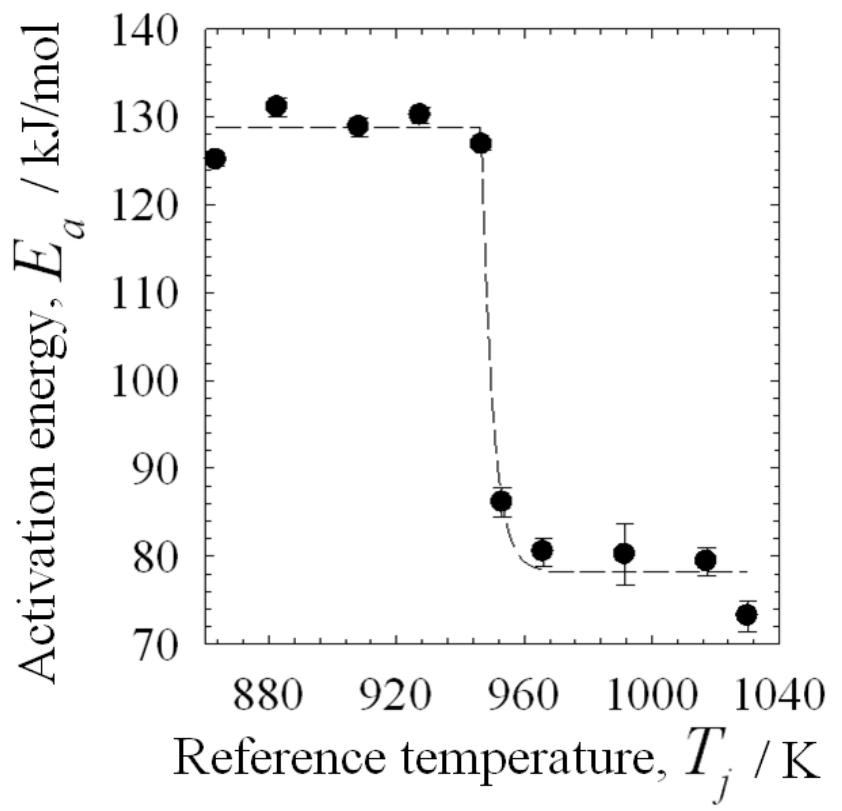


Figure 7: TGA in step mode for sample $\mathrm{LaMnO}_{3 \pm \delta}$. The solid line denotes the sample weight, the dotted line the thermal programme.

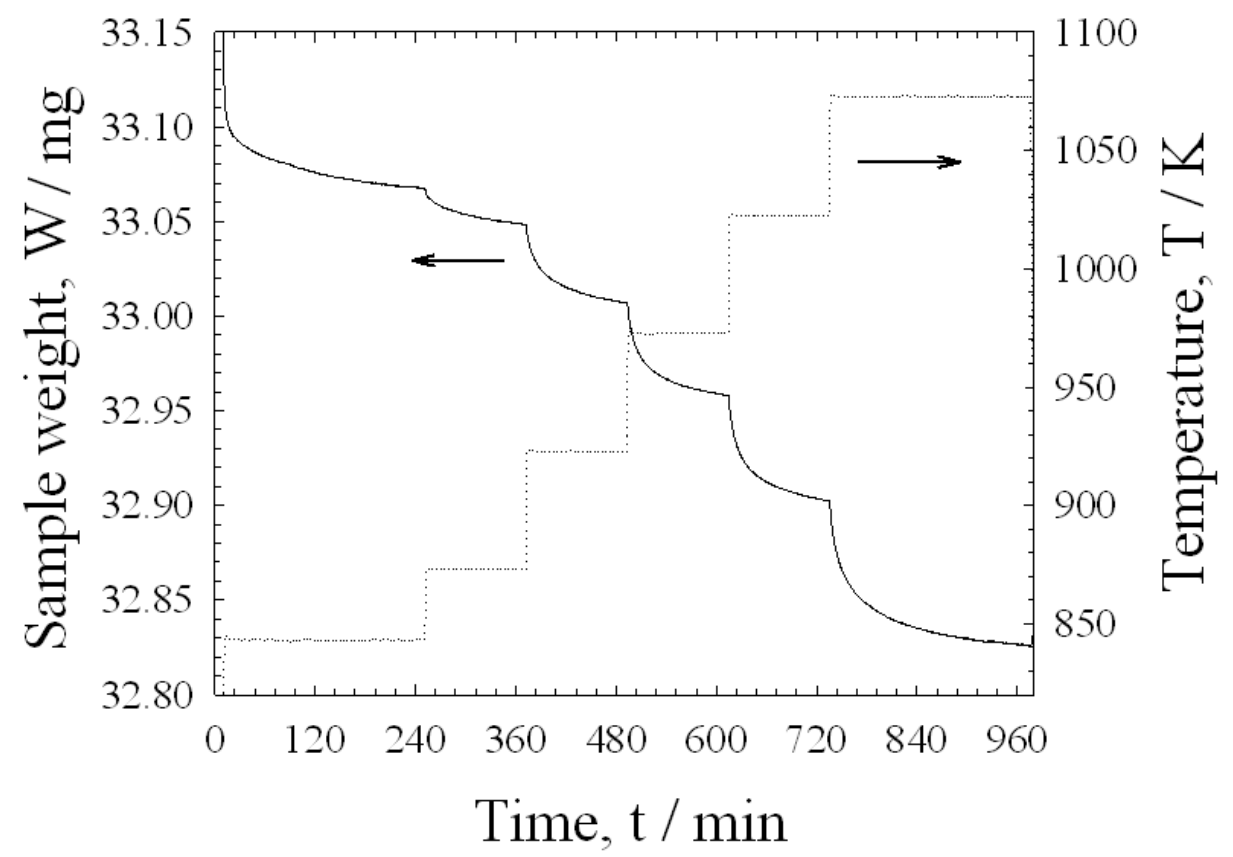


Figure 8: $(a)$ Conversion $(\alpha)$ as defined in Eq.10 vs. time $(t)$ at various temperatures; $(b)$ Conversion rate, as defined in Eq. 11, vs. conversion $(\alpha)$ at different temperatures: $T=873 \mathrm{~K}$ $(\bullet), T=923 \mathrm{~K}(\circ) T=973 \mathrm{~K}(\boldsymbol{\nabla}) T=1023 \mathrm{~K}(\Delta)$.

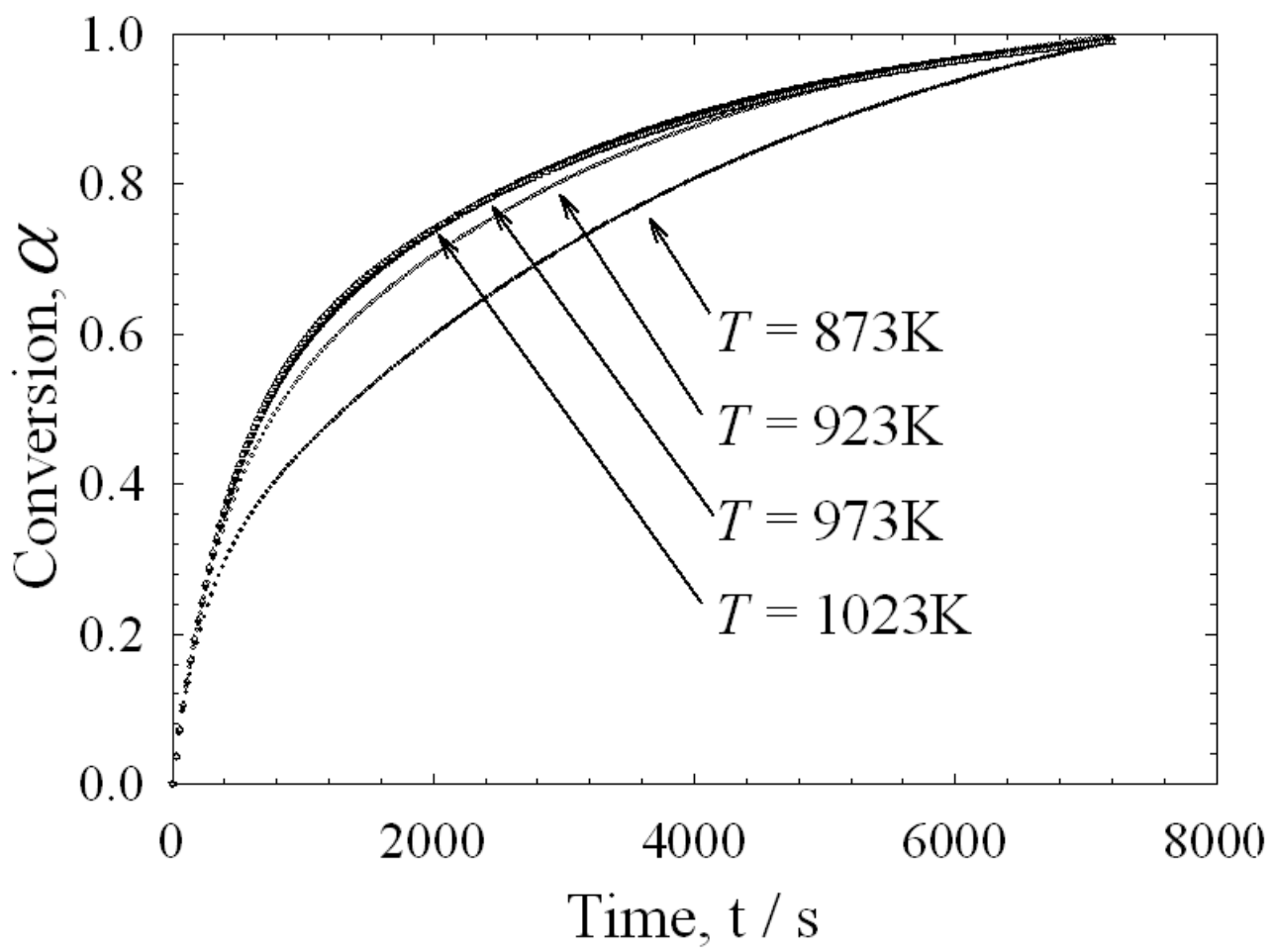

Fig. 8 (b)

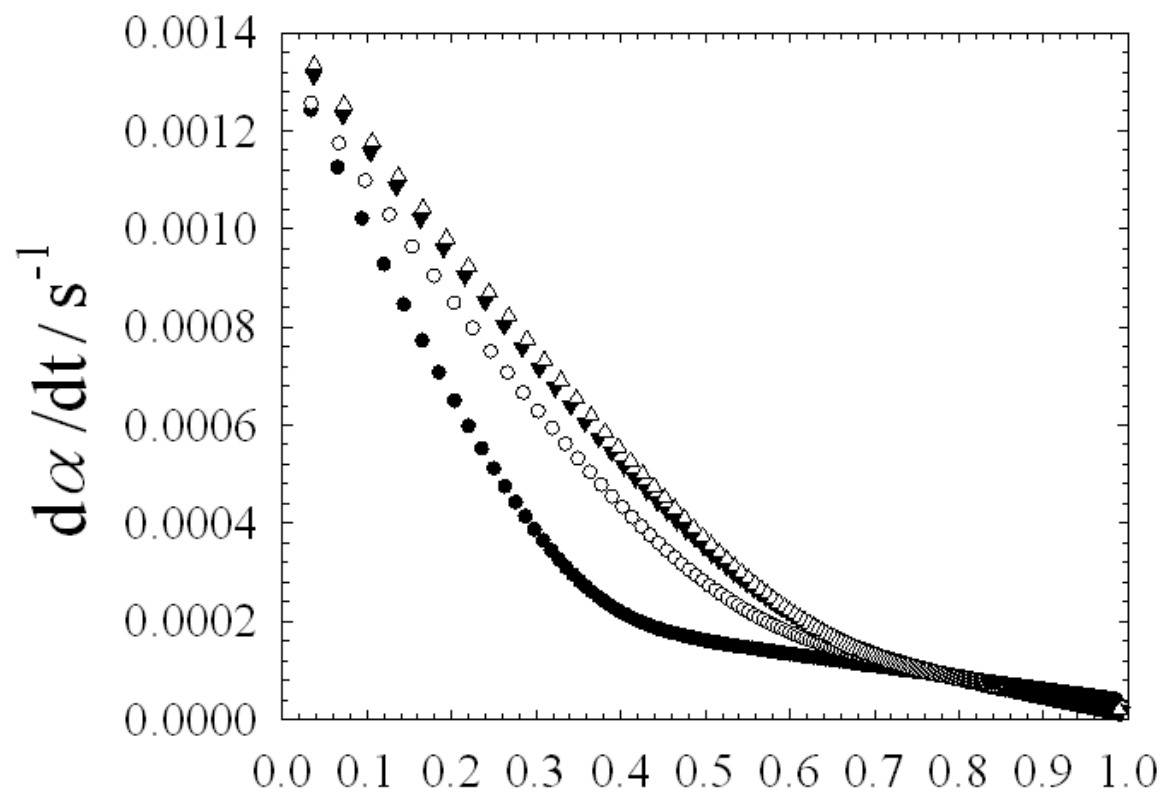

Conversion, $\alpha$ 
Figure 9: Logarithm of the conversion rate $\ln (d \alpha d d t)_{\alpha}$ for $\mathrm{LaMnO}_{3 \pm \delta}$ vs. reciprocal temperature $\left(1 / T_{\alpha}\right)$ at which the respective conversion was attained. The data points are reported from $\alpha=0.30$ to $\alpha=0.80$, with step $\Delta \alpha=0.10$.

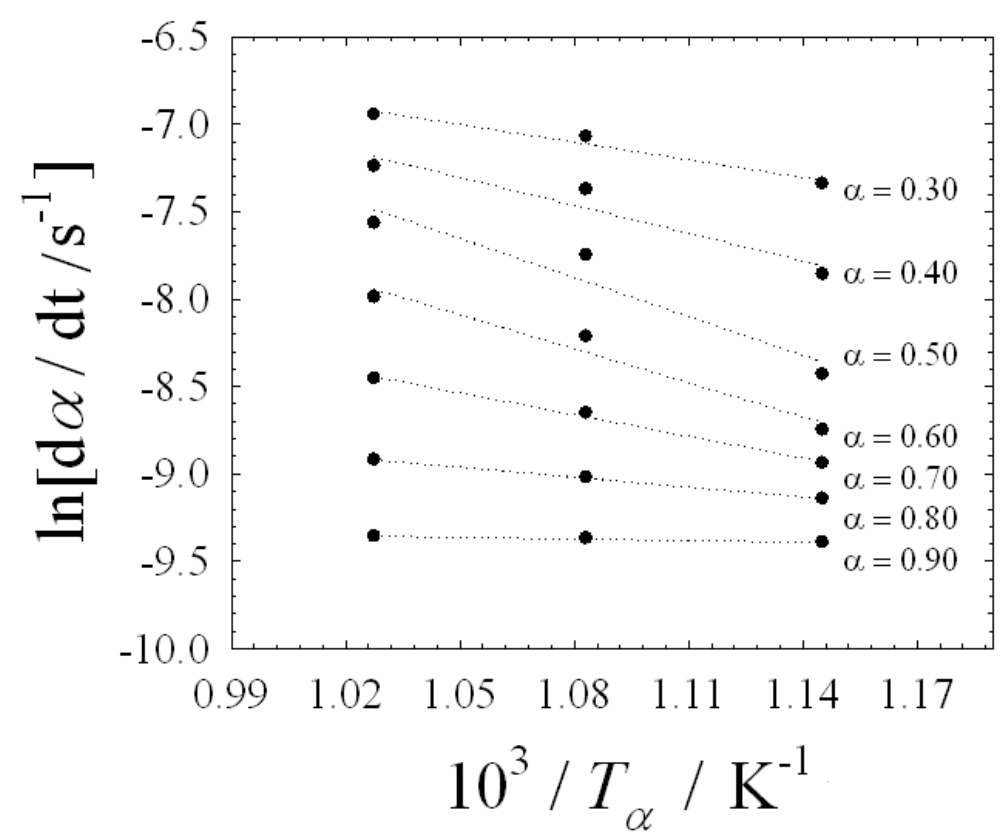

Figure 10: Hancock-Sharp plot for $\mathrm{LaMnO}_{3 \pm \delta}$, i.e. $\ln (-\ln (1-\alpha))$ vs. $\ln t(\alpha=$ conversion, $t=$ time $)$ at different temperature. $T=873 \mathrm{~K}(\bullet), T=923 \mathrm{~K}(\circ), T=973 \mathrm{~K}(\bullet), T=1023 \mathrm{~K}(\square)$.

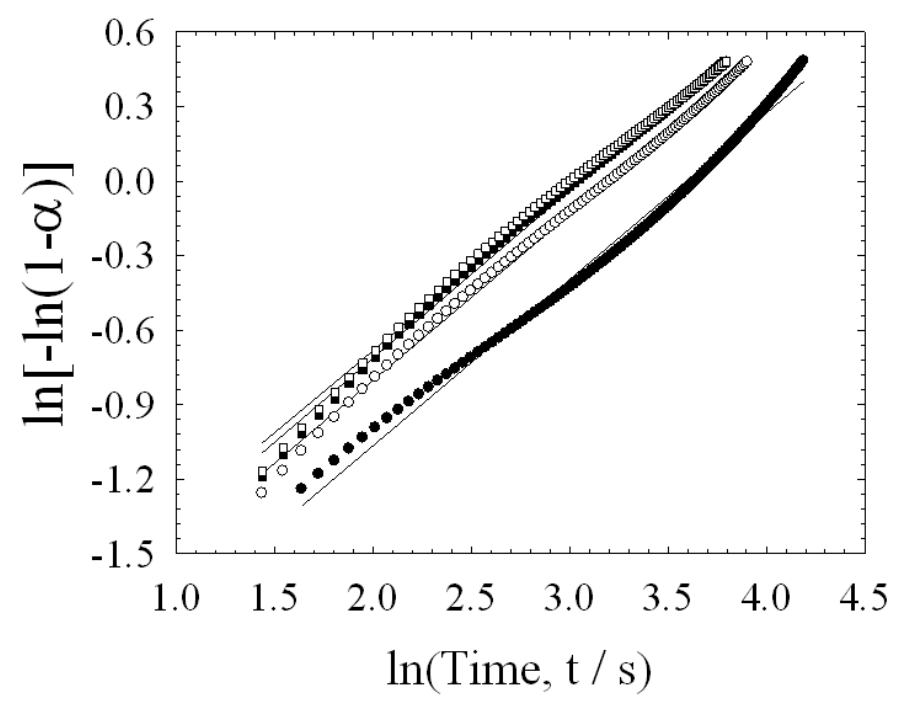


Figure 11: Comparison of $\mathrm{La}_{1-\mathrm{x}} \mathrm{Sr}_{x} \mathrm{MnO}_{3 \pm \delta}$ activation energy $\left(E_{a}\right)$ with literature data for oxygen diffusion as a function of $x$ : $(\diamond)[43],(\boldsymbol{\square}, \square)[44],(\boldsymbol{\Lambda}, \triangle)$ [31], $(\bigcirc)$ activation energy from the TPD data of this work $(\operatorname{Regime}(i))$.

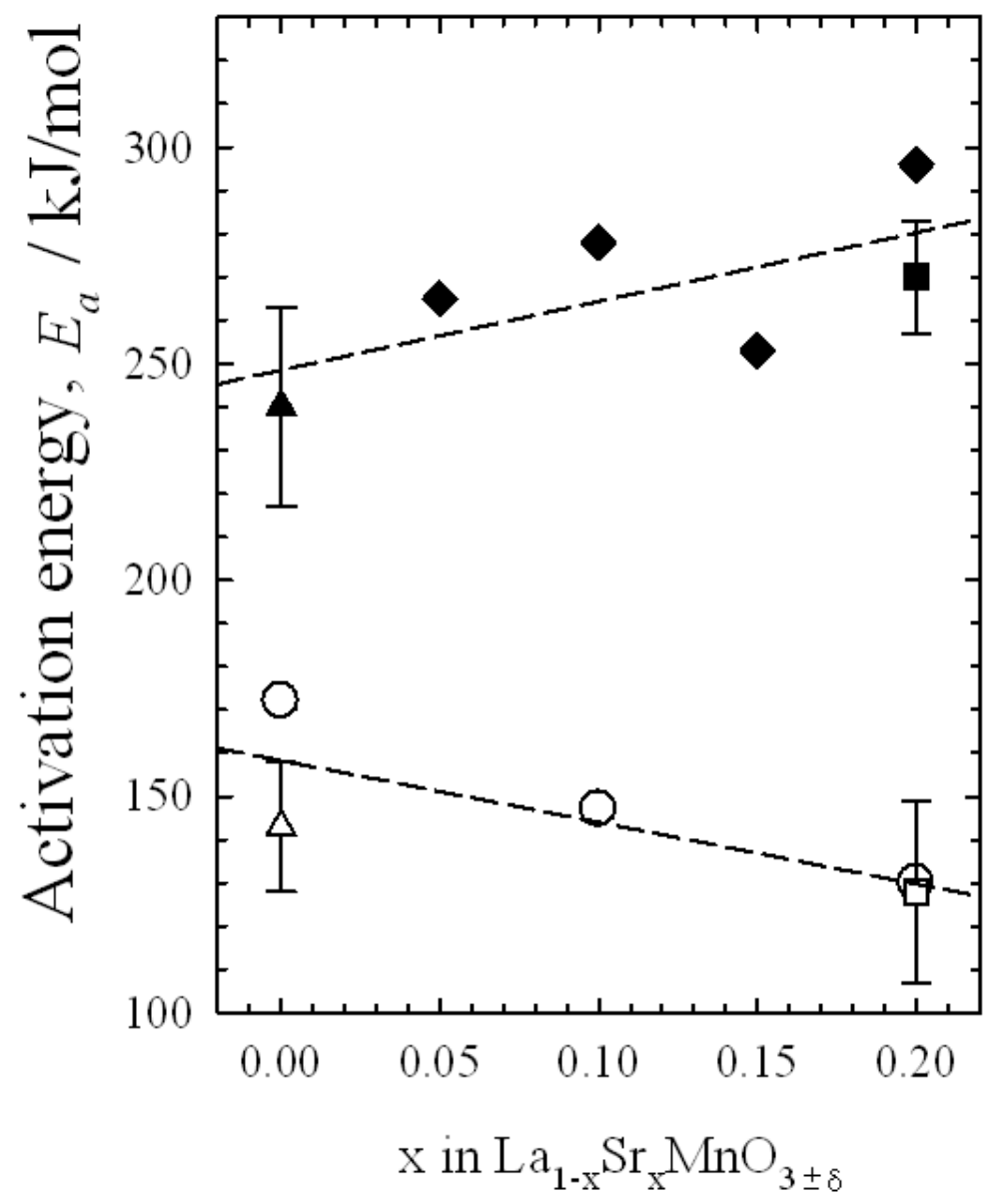


Figure 12: Activation energy $\left(E_{a}\right)$ for oxygen desorption estimated by different methods and

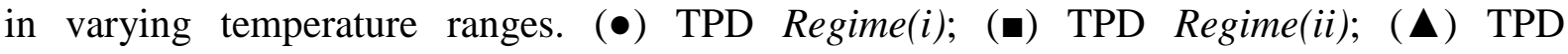
Regime(iii); ( $\square$ ) TGA-step; ( $\times$ ) TGA-ramp. For TGA-ramp the activation energy value obtained using model $D_{4}$ was chosen (see Table 5).

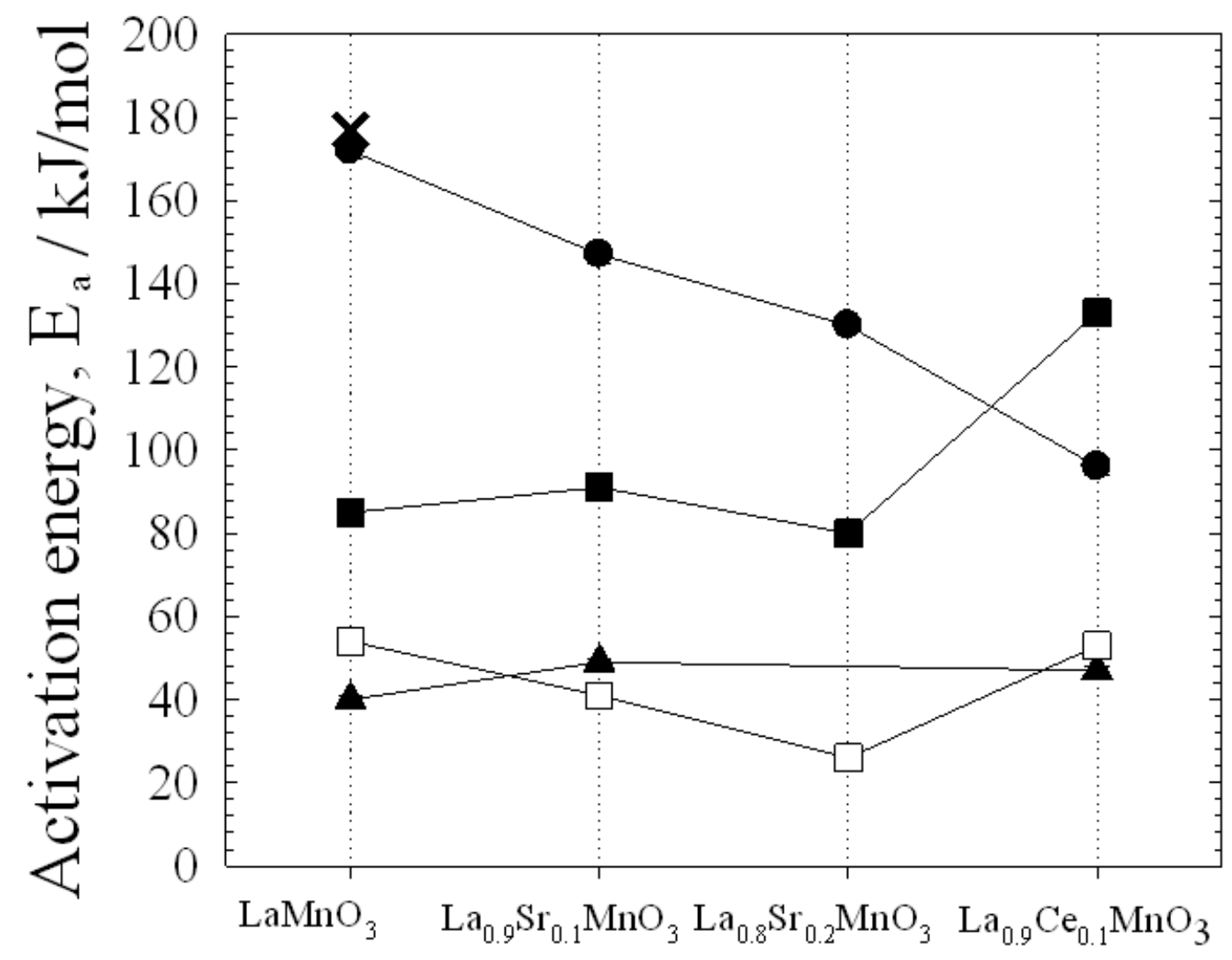




\section{LIST OF SYMBOLS}

\section{Latin letters}

$A, A^{\prime}$ : pre-exponential factor (units depending on the reaction order)

$D$ : kinetic constant for oxygen diffusion through the bulk

$E, E_{a}$ : activation energy $\left(\mathrm{kJ} \mathrm{mol}^{-1}\right)$. Other subscripts define the technique used for its evaluation.

$F(0)$ : molar flow of oxygen entering the reactor

$F(L)_{\mathrm{i}}$ : oxygen molar flow outcoming from the reactor at $T_{\mathrm{i}}$

$f(\alpha)$ : kinetic function or physical-geometrical model function

$g(\alpha)$ : integral function

$k\left(T_{i}\right)$ : kinetic constant

$N_{a d s}:$ moles of oxygen adsorbed on the surface

$N_{\text {mono }}$ : moles of oxygen adsorbed on the surface corresponding to a monolayer

$P_{0}$ : background oxygen partial pressure

$P_{i}$ : oxygen partial pressure at $\mathrm{T}_{\mathrm{i}}$

$r_{i}:$ reaction (desorption) rate at $\mathrm{T}_{\mathrm{i}}$

$V_{\text {sample }}:$ volume of the catalyst bed

\section{Greek letters}

$\alpha$. conversion

$v_{n}$ : vibration frequency of the activated intermediate (Eyring)

$\Theta=N_{a d s} / N_{\text {mono }}:$ surface coverage

$\tau(\mathrm{s}):$ contact time 